\title{
IMPLEMENTASI FITUR TES ONLINE DI SISTEM PENERIMAAN SISWA BARU PADA SMK MUHAMMADIYAH 1 PRAMBANAN KLATEN
}

\author{
(IMPLEMENTATION OF THE ONLINE TEST FEATURE IN THE ADMISSION OF NEW STUDENTS \\ AT SMK MUHAMMADIYAH 1 PRAMBANAN KLATEN)
}

\author{
Eka Wahyu Sholeha'), Ali Mustopa ${ }^{2)}$ \\ ${ }^{1)}$ Teknik Informatika, Politeknik Negeri Tanah Laut, \\ Jl. A. Yani No.Km.06, Pemuda, Kec. Pelaihari, Kabupaten Tanah Laut, Kalimantan Selatan 70815 \\ ${ }^{2)}$ Sistem Informasi, Universitas Amikom Yogyakarta, \\ J1 Ringroad Utara, Condongcatur, Depok, Sleman, Yogyakarta Indonesia 55283 \\ e-mail: ekawahyus@politala.ac.id ${ }^{1)}, \underline{\text { ali.m@amikom.ac.id }}{ }^{2}$
}

\begin{abstract}
ABSTRAK
Saat ini perkembangan Teknologi Informasi semakin memungkinkan untuk dapat menyampaikan informasi dengan lebih cepat. Dalam artike ini peneliti menganalisis bahwa permasalahan utama adalah lamanya waktu yang dibutuhkan untuk melakukan tes sedangkan keterbatasan pihak sekolah dari panitia, hal ini menyebabkan lamanya informasi tentang pendaftaran kelulusan, dimana membutuhkan waktu kurang lebih 1 bulan untuk menentukan proses kelulusan dari hasil tes. Ditambah dengan permasalahan kehilangan berkas pendaftaran yang terkadang diletakkan disembarang tempat menyebabkan hilang atau rusak berkas tersebut.

Proses pembuatan sistem ini peneliti menggunakan metode perancangan UML (Unified Modeling Language), perancangan tabel, dan antarmuka. Dalam penelitian ini peneliti juga menggunakan analisis PIECES untuk mengetahui permasalahan yang ada. Dengan menggunakan analisis PIECES sehingga penulis dapat menyimpulkan beberapa permasalahan dan menghasilkan berupa web "Tes Online di Sistem Penerimaan Siswa Baru pada SMK Muhammadiyah 1 Prambanan Klaten", yang dimaksudkan untuk membantu panitia menyelesaikan permasalahan utama yaitu dalam pelayanan penerimaan mahasiswa baru agar dapat memberikan informasi pendaftaran kelulusan secara cepat.
\end{abstract}

Kata Kunci: Tes Online, Penerimaan Siswa Baru, Analisis Pieces.

\begin{abstract}
Currently the development of Information Technology is increasingly possible to be able to convey information more quickly. In this article the researcher analyzes that the main problem is the length of time it takes to do the test while the limitations of the school from the committee, this causes the length of information about graduation registration, which takes approximately 1 month to determine the graduation process from the test results. Coupled with the problem of losing the registration file which is sometimes placed in any place causing the file to be lost or damaged.

The process of making this system, researchers use the UML (Unified Modeling Language) design method, table design, and interface. In this study, researchers also used PIECES analysis to find out the existing problems. By using PIECES analysis so that the author can conclude several problems and produce a web "Online Test in the New Student Admission System at SMK Muhammadiyah 1 Prambanan Klaten", which is intended to help the committee solve the main problem, namely in the service of new student admissions in order to provide graduation registration information.
\end{abstract}

Keywords: Online Test, New Student Admission, Pieces Analysis.

\section{Pendahuluan}

$\mathrm{S}$ MK (Sekolah Menengah Kejuruan) Muhammadiyah 1 Prambanan Klaten yang did rikan pada tahun 1997, yang mempunyai program keahlian Akuntansi dan sekretaris, dimana awalnya memiliki 3 kelas, dan saat ini menjadi 12 kelas dengan program keahlian Farmasi, Teknik Komputer Jaringan, Keuangan dan Administrasi Perkantoran. Dengan seiring waktu fasilitas-fasilitas pembelajar juga semakin lengkap dan berkembang. SMK Muhhamadiyah 1 Prambanan Klaten ini memiliki komitmen untuk lebih baik dan lebih baik lagi, menjadi patner 
bangsa untuk mendidik anak bangsa yang cerdas dan berakhlak mulia.

Pada proses penerimaan peserta didik baru (PPDB) di SMK Muhhamdiyah 1 Prambanan Klaten ini masih dilakukan dengan cara calon pendaftar datang langsung ke sekolah untuk melihat syarat dan mengisi formulir pendaftaran sehingga waktu yang dibutuhkan dalam proses pendaftaran hingga pendaftar mendapatkan hasil pengumuman sangat lama, hal itu belum termasuk memberikan tes wawancara kepada setiap calon siswa dengan keterbatasan panitia dan waktu yang dibutuhkan para panitia untuk memasukkan data seluruh pendaftar ke dalam Ms Excel, dengan cara tersebut kemungkinan terjadi kesalahan lebih besar dibandingkan dengan sebuah aplikasi komputer. Ini jelas tidak efisien dalam hal waktu, sehingga banyak waktu yang terbuang sia-sia dan akan muncul kesulitan lain seperti banyak terjadi kesalahan dalam pencatatan, menghambat proses pengambilan keputusan kelulusan pendaftar.

Kemudahan akses internet yang semakin luas dari tahun ketahun membuat penulis ingin merancang sebuah sistem Sistem Informasi Pendaftaran Siswa Baru berbasis web yang dapat diakses dimana saja sehingga lebih efektif dan efesien. Dengan adanya sistem ini diharapkan dapat meningkatkan pelayanan yang ada di SMK Muhammadiyah 1 Prambanan Klaten, pada proses pengisian data pendaftar dapat dilakukan di berbagai tempat dan kapanpun sesuai jadwal pendaftaran yang telah ditentukan. Pada penerapan aplikasi ini bisa dilakukan secara cepat karena sebagian besar guru telah terbiasa menggunakan komputer maupun internet. Struktur dari sistem ini nantinya juga akan disesuaikan dengan ketentuan proses pendaftaran.

Beberapa peneliti membuat sistem informasi untuk membantu mempercepat pada proses pelayanan pendaftaran pesera didik baru. Najamudin, dkk [1] mengembangkan sistem pendaftaran peserta didik baru berbasis web pada SMKN 2 Kuripan Lombok Barat NTB. Dengan alur dasar yang mengacu pada sistem konvensional yang sudah diterapkan sebelumnya. Pengujian menggunakan Black Box yang menunjukkan bahwa sistem dapat berjalan sesuai kebutuhan. Dwi Arum Ningtyas, dkk [2] membuat sebuah sistem informasi penerimaan peserta didik baru pada SMP AR-RIDHA dengan tujuan untuk mempermudah calon peserta didik baru dan pihak sekolah dalam melakukan proses penerimaan peserta didik baru secara online. Zulfikar
Sembiring [3] membuat sistem informasi manajemen sekolah untuk layanan penerimaan peserta didik baru untuk mengoptimalkan sistem informasi dan teknologi infromasi guna mendukung kegiatan operasional sekolah dan menjadi lebih trasnparan.

\section{STUDI PUSTAKA}

Aplikasi yang digunakan dan diterapkan pada RA Sirojul Falah menggunakan bahasa pemrograman PHP, MySQL, Framework Codeigniter dan Library Bootsrap dan menggunakan rancangan antarmuka ERD, LRS serta UML. Sistem berhasil diterapkan pada RA Sirojul Falah. Sistem informasi ini diharapkan dapat mengolah data siswa baru menjadi lebih baik dan lebih praktis agar dapat membantu panitia PPDB [4].

Sistem Informasi PPDB pada Yayasan Pendidikan Arya Jaya Sentika dapat melakukan pendaftaran secara online. Dapat menampilkan informasi biaya dana sumbangan pendidikan dan orang tua calon siswa baru dapat mengetahuinya. Kemudian sistem dapat mengirimkan notifikasi via email ketika selesai melakukan pembayaran dan bukti pembayaran dapat dicetak [5].

Sistem PPDB Online pada SMK Negeri 6 Makassar ini memiliki 4 jalur yaitu; Jalur Afirmasi, Jalur Khusus, Prestasi dan Akademil. Sistem ini terhubung dengan database Dinas Sosial dan Dinas Pendidikan, Kemenag dan Koni [6].

Sistem PPDB pada SMPN 2 Selogiri memiliki fitur infromasi kisi-kisi ujian yang dapat memudahkan siswa untuk belajar ketika sebelum ujian. Fitur SMS Gateway yang berguna bagi siswa atau wali mendapatkan informasi dari sekolah [7].

Dengan adanya sistem PPDB di MAN 2 Model Banjarmasin dikatakan efektif dikarenakan memiliki nilai lebih dari 50\% dalam persentase $1-100 \%$ ketika menggunakan digabungkan dengan metode Weight Product [8].

Jenjang SMA/SMK Negeri Jawa Timur berhasil membangun sistem pendaftaran online untuk PPDB dengan mengadopsi konsep objek oriented programming (oop) menggunakan framework codeigniter. Dengen menggunakan teknik pengjuan blackbox dapat dipastikan sistem telah berjalan dengan baik. Adapun beberapa permasalahan yang terjadi diantaranya ketika proses unggah berkas yang memiliki ukuran file besar dapat menyebabkan sistem memiliki penurunan kualitas kecepatan [4]. 
Berdasarkan hasil penelitian PPDB online di SMP Negeri 21 Samarinda yang memiliki tujuan bagaimana implementasi PPDB secara online dengan melakukan pengidentifikasian masalah sebelumnya. Maka dapat disimpulkan dapat berjalan dengan baik, karena didukung dengan sarana prasarana yang baik dari sekolah [9].

Pada tahun 2020 di Indonesia mengalami pandemik Covid-19 yang mengharuskan administrasi menjadi online. Sehingga SD Semangat Bangsa dan TK kartini merancang aplikasi PPDB berbasis web agar dapat dibuka dimanapun dan dapat membuat proses menjadi lebih cepat. Setelah pengimpelementasian PPDB secara online dalam pemantauan 7 hari, pihak sekolah menyatakan bahwa pendaftar bertambah 4 kali lipat dari sebelumnya [10].

\section{METODE PENELITIAN}

Teknik analisis data dalam penelitian ini akan mengidentifikasi informasi yang diperlukan untuk menentukan penggunaan sistem. Data yang diperoleh untuk penelitian ini dikumpulkan dari data-data yang ada di Sekolah mengenai penerimaan peserta didik baru, kemudian melakukan klarifikasi dengan pihak terkait yaitu pantia peserta didik baru, sehingga menghasilkan data yang diinginkan.

Langkah-langkah yang penulis lakukan dalam penyusunan penelitian ini adalah sebagai berikut:

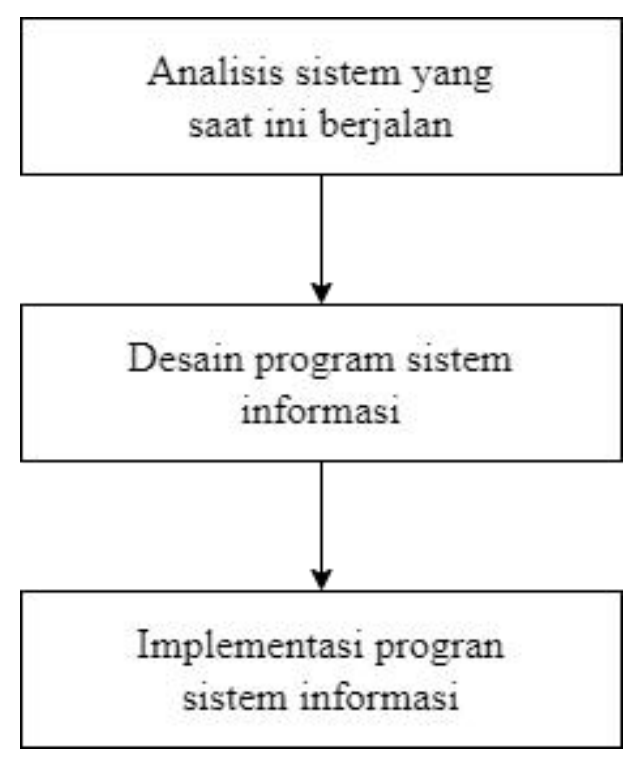

Gambar 1. Metodologi Penelitian
1. Analisis sistem yang saat ini berjalan

Analisis yang dilakukan oleh penulis yaitu menggunakan Analisis Pieces untuk mengetahui permasalahan pada sistem yang saat ini berjalan di SMK Muhammadiyah 1 Prambanan Klaten. Kemudian melakukan pengumpulan data-data yang diperlukan untuk membuat sistem penerimaan siswa baru menggunakan web.

2. Desain program sistem informasi

Tahap ini penulis melakukan perancangan program untuk sistem informasi penerimaan siswa baru agar sesuai dengan kebutuhan yang ada.

3. Implementasi progran sistem informasi

Pada tahap ini adalah pengimplementasian dari analisis dan desain program ditahap sebelumnya. Pengimplementasian ini diimplementasikan ke dalam bahasa pemrograman PHP agar dapat menjadi sistem informasi berbasis website. Di bagian fitur tes onlinenya diimplementasikan dengan bahasa pemrograman PHP dan JavaScript.

\section{HASIL DAN PEMBAHASAN}

Untuk membuat sebuah sistem agar dapat memecahkan masalah pada SMK Muhammadiyah 1 Prambanan Klaten, maka menggunakan analisis kebutuhan sistem, perancangan sistem dan tahap akhir adalah pengimplementasian ke dalam sistem. $A$. Analisis Kebutuhan Sistem

1) Kebutuhan Fungsional

Analisis kebutuhan fungsional adalah analisis terhadap sistem yang akan dibuat, layanan atau fitur apa saja yang terdapat pada sistem. Kebutuhan fungsional sistem diantaranya :

1. Sistem dapat menampilkan soal test secara acak.

2. Sistem ini mampu memanajemen data pendaftar, data soal dan data hasil tes ke dalam database server lokal.

3. Sistem ini memiliki hak akses login admin (panitia).

4. Sistem dapat melakukan aksi input, edit, update, dan delete data sebagai hak akses admin untuk data calon siswa.

5. Sistem mampu mencetak hasil tes, baik secara keseluruhan maupun secara filter tanggal.

2) Kebutuhan Non Fungsional 
Analisis kebutuhan non fungsional 3) ERD merupakan sebuah kebutuhan minimum mengenai perangkat keras (Hardware) dan perangkat lunak (Sofware) untuk mendukung jalannya sebuah sistem.

1. Kebutuhan perangkat keras

Processor: Intel Pentium Dual Core RAM: $1 \mathrm{~GB}$

Harddisk : 500 GB

2. Kebutuhan perangkat lunak

Sistem Operasi : Windows XP

Web Server : XAMPP

Database : MySQL

Web Editor : sublime

Web Browser: Mozilla Firefox

B. Perancangan Sistem

1) UML (Unifiend Model Language)

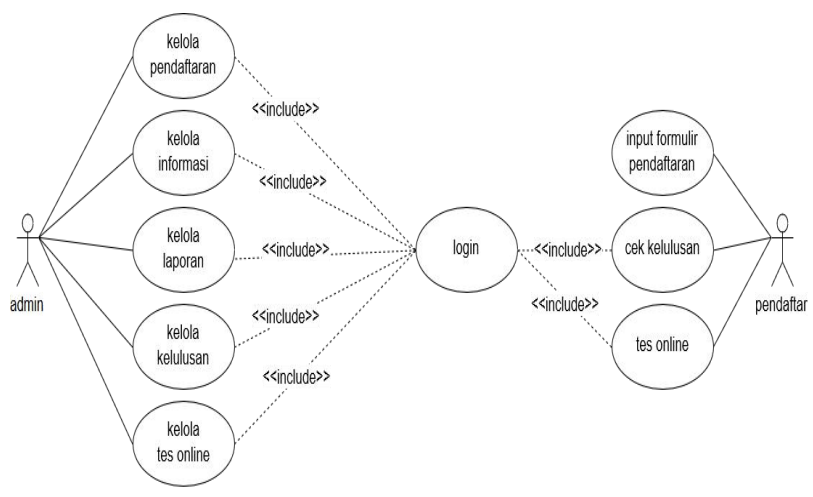

Gambar 2. Use Case Diagram

2) Relasi Antar Tabel



Gambar 3. Relasi Antar Tabel

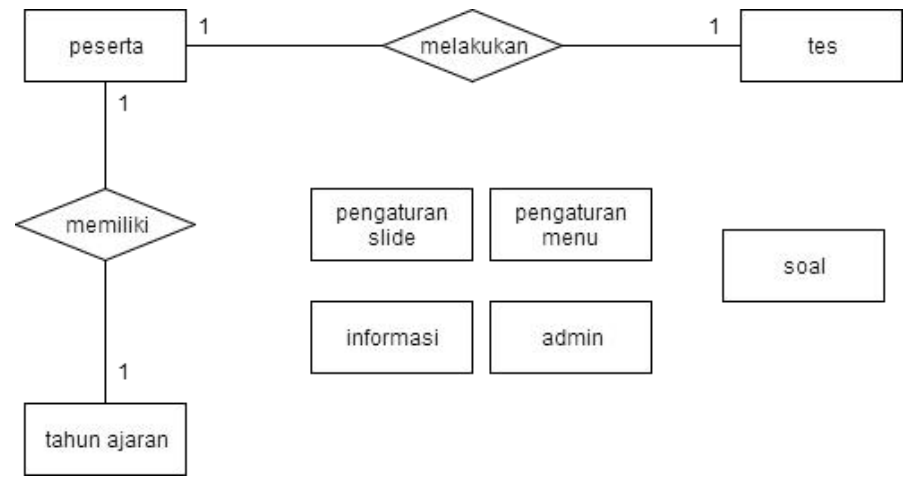

Gambar 4. ERD

C. Implementasi dan Pembahasan

1) Implementasi Jaringan

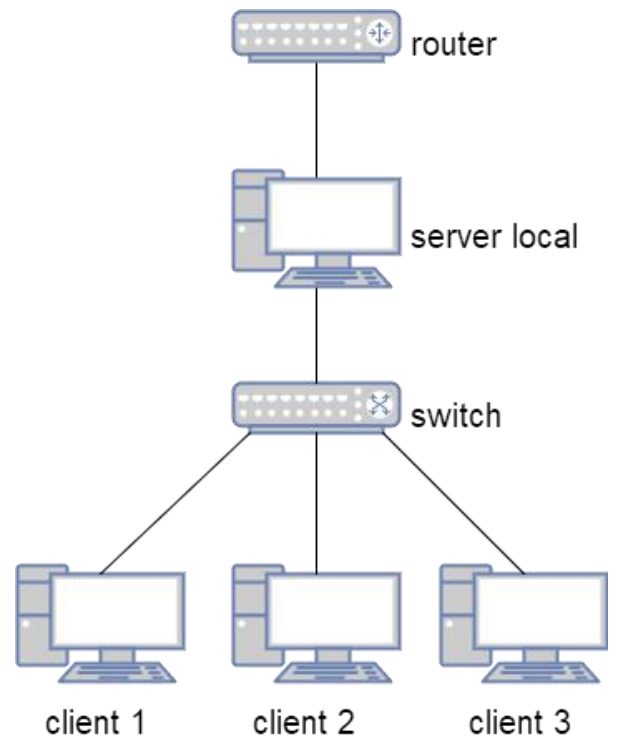

Gambar 5. Implementasi Server Lokal

2) Implementasi Database

Untuk keperluan sistem menggunakan basis data dan tabel. Database ini digunakan menyimpan data admin, data informasi, data pengaturan, data peserta, data soal dan data tes. Database sistem ini menggunakan salah satu DBMS yaitu MySQL.

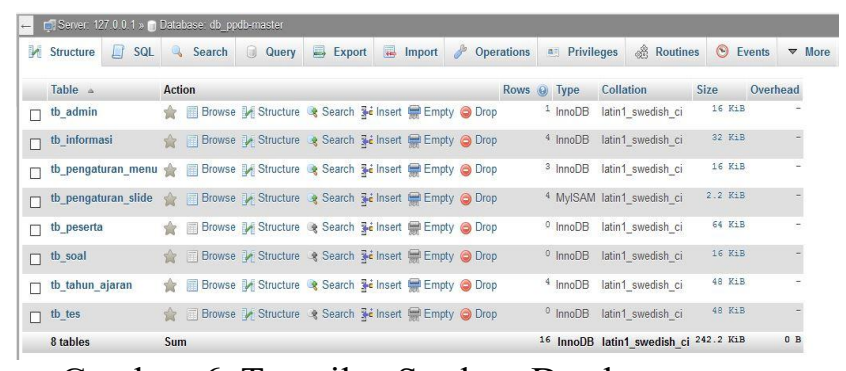

Gambar 6. Tampilan Struktur Database Penerimaan Siswa Baru dan Tes Online 
Sholeha, Mustopa — Implementasi Fitur Tes Online Di Sistem Penerimaan Siswa Baru Pada SMK Muhammadiyah 1 Prambanan Klaten

\section{3) Implementasi Fitur Tes Online}

Fitur tes online dapat digunakan ketika peserta atau calon siswa sudah melakukan pembayaran. Dimana nantinya akan diminta menginputkan kode tes yang ada pada lembar bukti pembayaran yang diberikan oleh pihak sekolah.



Gambar 7. Butkti Pembayaran

Gambar 8. Tampilan pendaftar untuk menginput kode tes

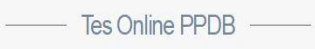

$$
\text { Biodata }
$$



Gambar 9. Tampilan pendaftar berhasil menginputkan kode tes



Gambar 10. Tampilan cara pengerjaan tes online

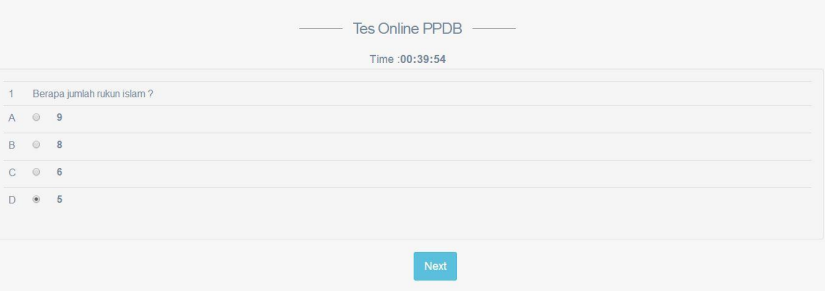

Gambar 11. Tampilan saat pengerjaan tes online

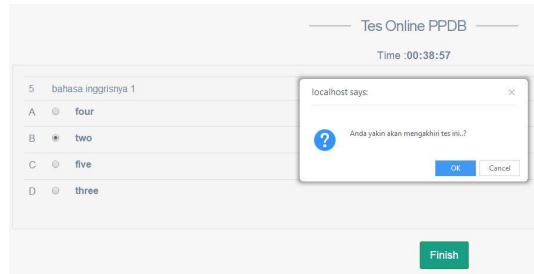

Gambar 12. Tampilan saat peserta selesai mengerjakan tes dan menekan tombol finish

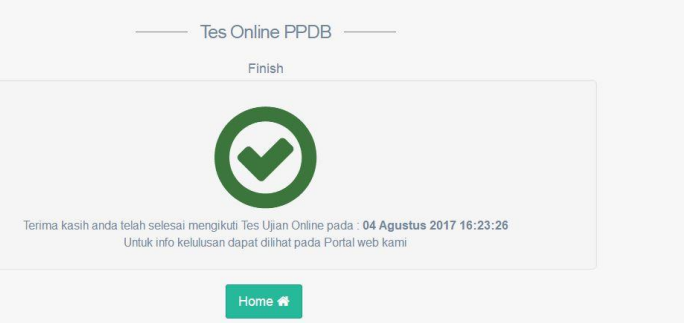

Gambar 13. Tampilan peserta saat menyelesaikan tes online

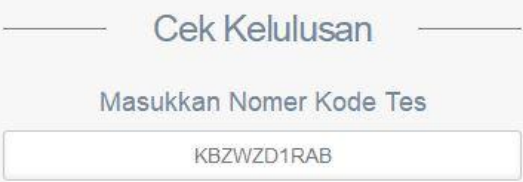

Gambar 14. Tampilan untuk cek kelulusan dari hasil tes online 


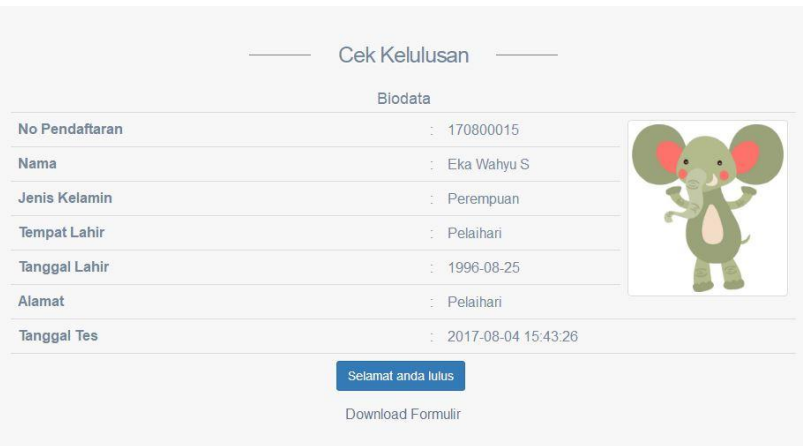

Gambar 15. Tampilan hasil pengumuman kelulusan

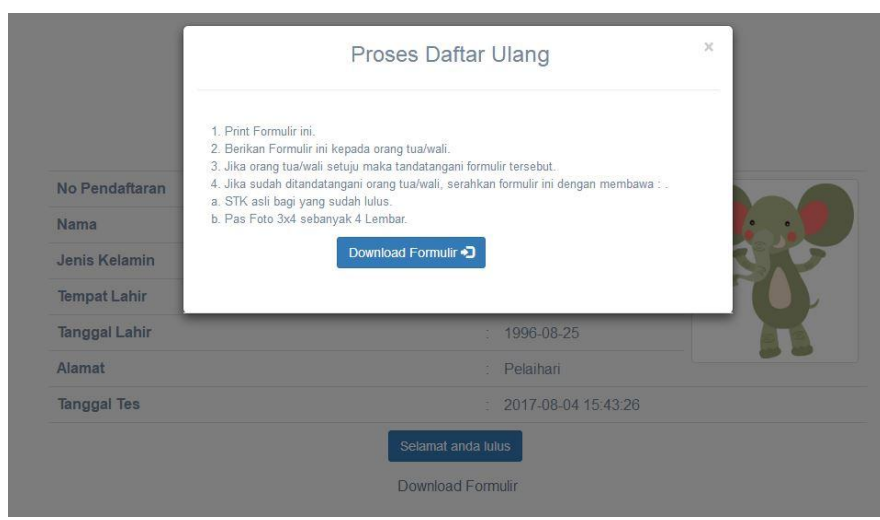

Gambar 16. Tampilan saat download formulir untuk melanjutkan ke tahap daftar ulang

D. Pengujian

Pengujian digunakan untuk mengetahui, sistem yang sudah dirancang berjalan dengan baik. Pengujian yang digunakan untuk penelitian ini adalah pengujian skenario yaitu teknik pengujian perangkat lunak membuat skenario. Skenario membantu sebuah sistem untuk mudah dievaluasi. Berikut daftar pengujian testing skenario yang digunakan :

Tabel 1. Daftar pengujian skenario

\begin{tabular}{|c|l|}
\hline No. & \multicolumn{1}{|c|}{ Pengujian } \\
\hline 1. & Login admin \\
\hline 2. & Import soal file excel \\
\hline 3. & Tes online \\
\hline
\end{tabular}

1) Skenario login admin

Login username dan password yang salah.

Tabel 2. Skenario pengujian 1

\begin{tabular}{|l|l|}
\hline Skena & Login dengan username dan password yang \\
rio & salah. \\
Pengu & \\
jian & \\
\hline
\end{tabular}

\begin{tabular}{|l|l|}
\hline $\begin{array}{l}\text { Test } \\
\text { Case }\end{array}$ & \multicolumn{1}{|c|}{ Login Admin } \\
\hline $\begin{array}{l}\text { Hasil } \\
\text { yang } \\
\text { dihara } \\
\text { pkan }\end{array}$ & $\begin{array}{l}\text { Sistem akan menolak akses login dan } \\
\text { menampilkan pesan "Username dan Password } \\
\text { salah". }\end{array}$ \\
\hline $\begin{array}{l}\text { Hasil } \\
\text { Pengu } \\
\text { jian }\end{array}$ & \multicolumn{1}{|c|}{ LoginAdmin } \\
\hline $\begin{array}{l}\text { Kesim } \\
\text { pulan }\end{array}$ & valid \\
\hline
\end{tabular}

Login dengan username atau password yang benar.

Tabel 3. Skenario pengujian 2

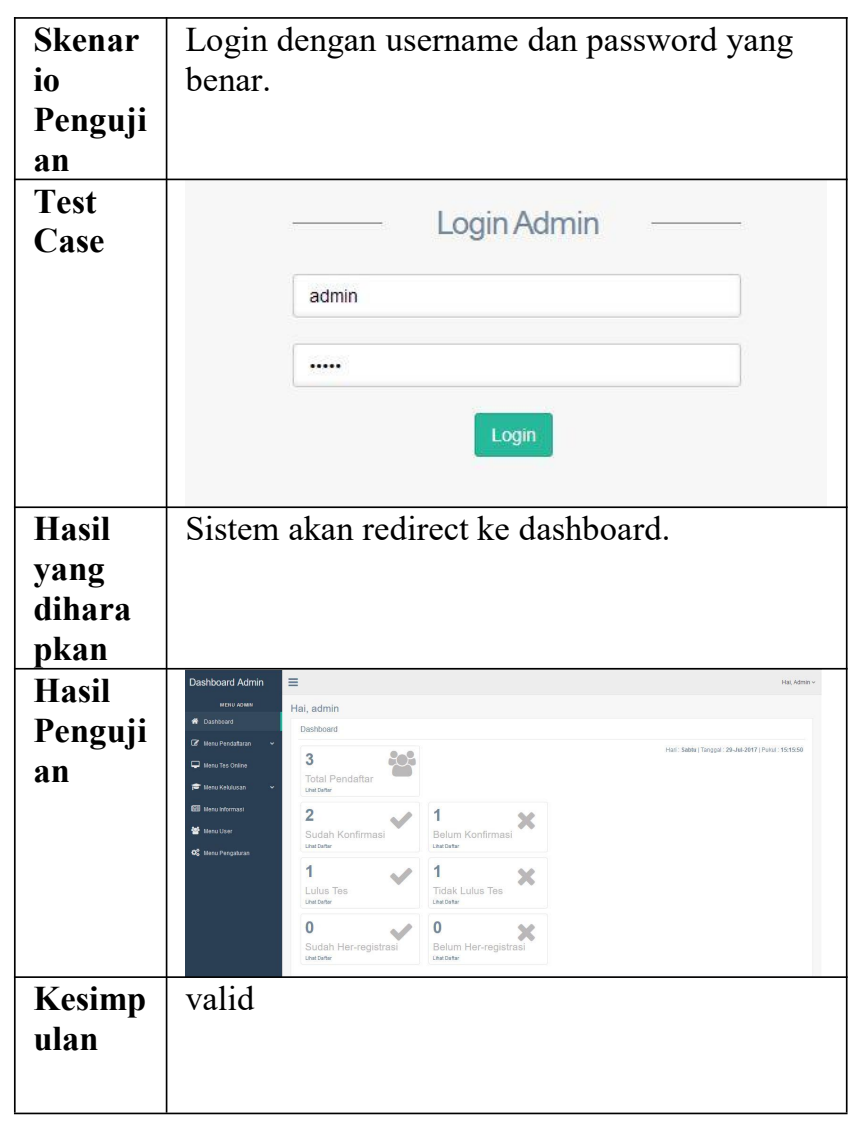

2) Skenario import soal dari file excel Import data soal tidak sesuai dengan template yang dibuat. 


\section{Tabel 4. Skenario pengujian 1}

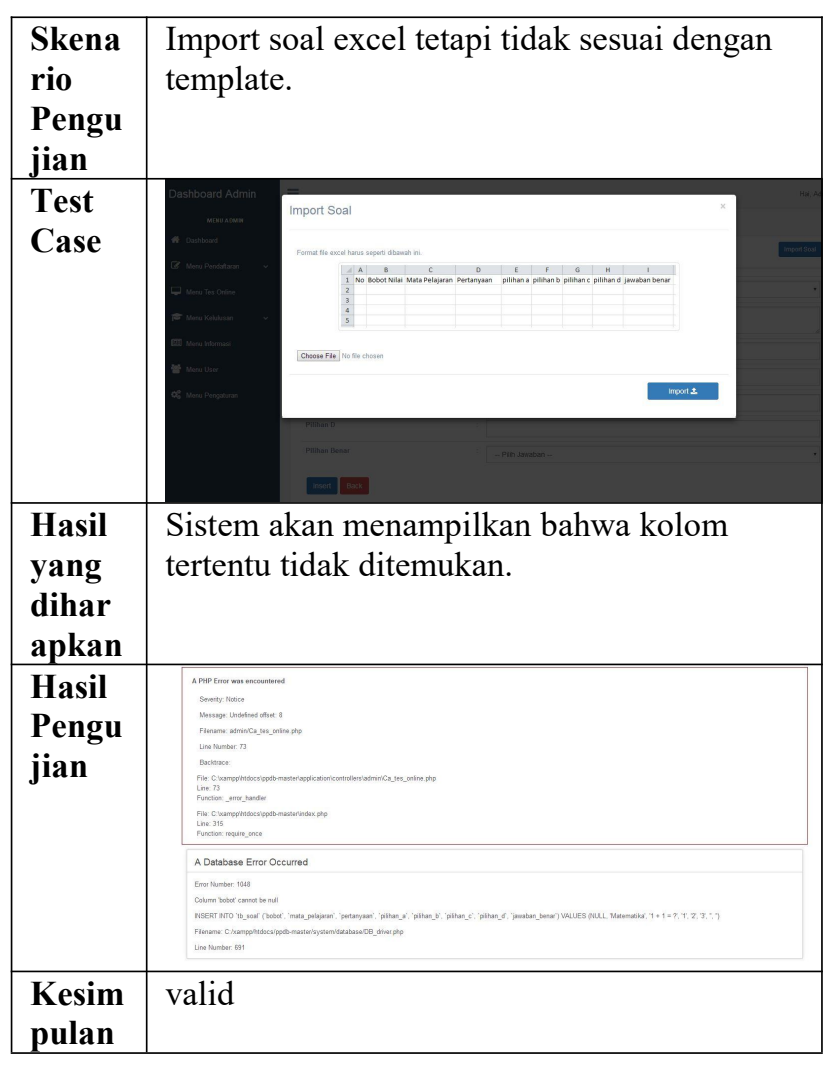

2. Import data soal sesuai dengan template.

Tabel 5. Skenario pengujian 2

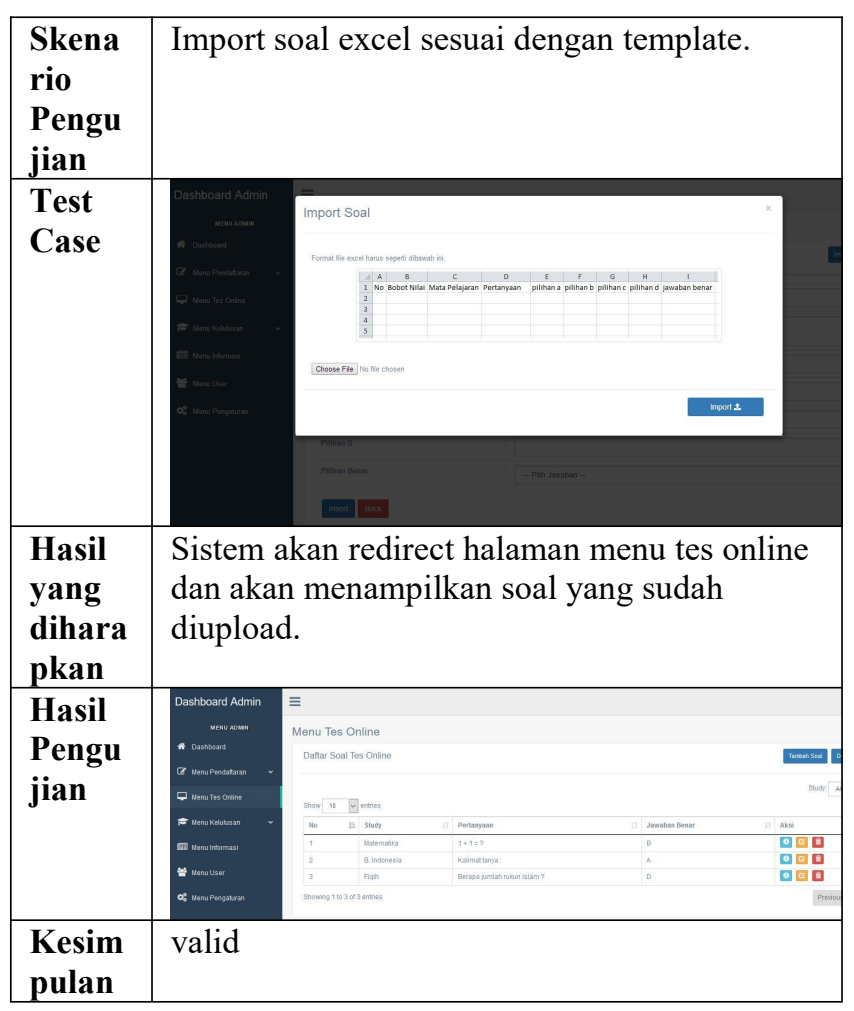

\section{3) Skenario tes online}

Saat melakukan tes, peserta mencoba melakukan klik button back pada browser
Tabel 6. Skenario pengujian 1

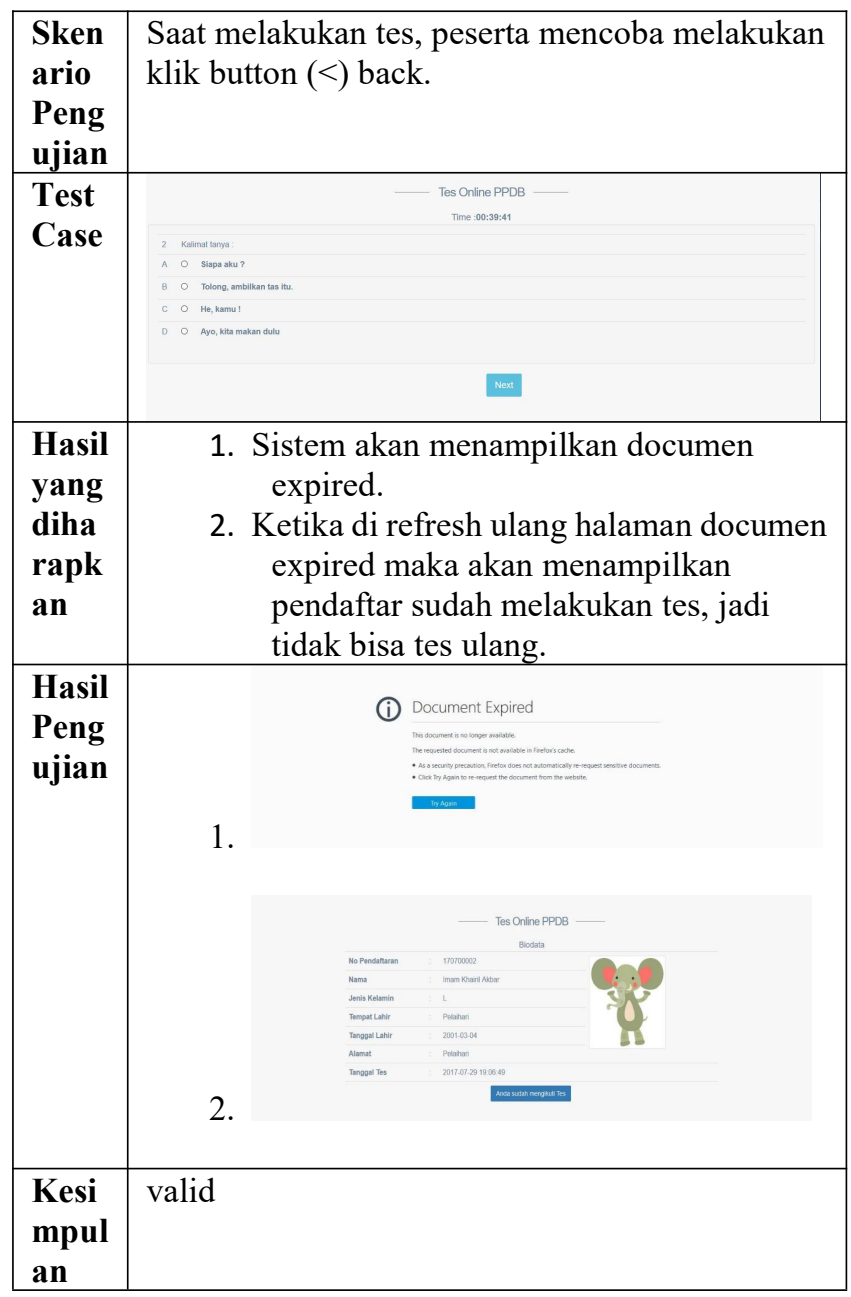

\section{Kesimpulan}

Berdasarkan pembahasan penelitian ini menghasilkan sistem penerimaan siswa baru pada SMK Muhammadiyah 1 Prambanan Klaten dengan menggunakan fitur tes online dan mengupload soal tes menggunakan file excel. Sistem ini mampu menampung data ppdb dan tes inline untuk keperluan kelengkapan data yang dibutuhkan panitia dan mampu menambah, merubah serta menghapus data yang ada dalam sistem ini. Sistem ini dirancang untuk mempermudah dalam segi pelayanan dan mampu membantu kinerja panitia ppd dalam mempersingkat waktu sehingga mempercepat pengumuman hasil kelulusan.

Dalam penelitian ini memiliki saran untuk peneliti selanjutnya yaitu pada bagian tes online, admin dapat mengategorikan soal ujian untuk masing-masing jurusan. 


\section{DAFTAR PUSTAKA}

[1] N. Najamudin, W. Bagye, and M. Ashari, "APLIKASI PENERIMAAN PESERTA DIDIK BARU BERBASIS WEB PADA SMK NEGERI 2 KURIPAN," J. Manaj. Inform. dan Sist. Inf., vol. 2, no. 2, 2019, doi: 10.36595/misi.v2i2.100.

[2] D. A. Ningtyas, M. Badrul, and D. N. Sulistyowati, "Sistem Informasi Penerimaan Peserta Didik Baru Pada Smp Ar-Ridha Jakarta," Techno Nusa Mandiri, vol. Vol 15, no. 1, 2018.

[3] S. Sukri and Z. Zulfikar, "Mendapatkan Peringkat Terbaik Website Pada Search Engine Dengan Metode Search Engine Optimization (SEO)," J. Nas. Komputasi dan Teknol. Inf., vol. 4, no. 3, 2021, doi: 10.32672/jnkti.v4i3.2973.

[4] K. Puspita, Y. Alkhalifi, and H. Basri, "Rancang Bangun Sistem Informasi Penerimaan Peserta Didik Baru Berbasis Website Dengan Metode Spiral," Paradig. - J. Komput. dan Inform., vol. 23, no. 1, 2021, doi: 10.31294/p.v23i1.10434.

[5] T. Hidayat, M. Muttaqin, and D. Djamaludin, "Sistem Informasi Penerimaan Peserta Didik Baru Online Berbasis Website di Yayasan Pendidikan Arya Jaya Sentika," Komputika J. Sist. Komput., vol. 9, no. 1, 2020, doi: 10.34010/komputika.v9i1.2750.

[6] N. R. Ansar, "Implementasi Manajemen Penerimaan Peserta Didik Baru Berbasis Online di SMK Negeri 6 Makassar," J. Din. Manaj. Pendidik., vol. 4, no. 1, 2019, doi: 10.26740/jdmp.v4n1.p65-72.

[7] R. Benarivo, "Rancang bangun sistem informasi dan penerimaan peserta didik baru berbasis web," Electron. Theses Diss. Univ. Muhammadiyah Surakarta, 2018.

[8] R. Fauzan, R. Fitri, and M. Fadliansyah, "Sistem Informasi Penjurusan Dan Penerimaan Peserta Didik Baru Menggunakan Metode Weighted Product," J. ELTIKOM, vol. 1, no. 1, 2017, doi: 10.31961/eltikom.v1i1.15.

[9] M. Jannah, E. Erawan, and H. Burhanuddin, "Implementasi Program Penerimaan Peserta Didik Baru (Ppdb) Online Di Smp Negeri 21 Samarinda," Ejournal.Ap.Fisip-Unmul.Ac.Id, vol. 8, no. 3, 2020.

[10] A.-K. Al-Khowarizmi, "Implementasi Penerimaan Peserta Didik Baru (PPDB) Berbasis Web pada Sekolah Dasar Alam Semangat Bangsa dan Taman Kanak-Kanak Kartini Kecamatan Medan Johor,' J. Pengabdi. Barelang, vol. 2, no. 03, 2020, doi: 10.33884/jpb.v2i03.1985. 